\title{
Targeted Therapy For RET-Rearranged Non-Small Cell Lung Cancer: Clinical Development And Future Directions
}

This article was published in the following Dove Press journal: OncoTargets and Therapy

\author{
Christoph Jakob \\ Ackermann' \\ Gustavo Stock ${ }^{2}$ \\ Rebecca Tay' \\ Mohammed Dawod' \\ Fabio Gomes' \\ Raffaele Califano (D) ${ }^{1,3,4}$ \\ 'Department of Medical Oncology, The \\ Christie NHS Foundation Trust, \\ Manchester, UK; ${ }^{2}$ Department of Medical \\ Oncology, Instituto do Câncer do Estado \\ de São Paulo, São Paulo, Brazil; \\ ${ }^{3}$ Department of Medical Oncology, \\ Manchester University NHS Foundation \\ Trust, Manchester, UK; ${ }^{4}$ Division of \\ Cancer Sciences, University of \\ Manchester, Manchester, UK
}

\begin{abstract}
Approximately 1-2\% of unselected patients with Non-small Cell Lung Cancer (NSCLC) harbor RET rearrangements resulting in enhanced cell survival and proliferation. The initial treatment strategy for RET rearranged NSCLC has been multi-target tyrosine kinase inhibition. With overall response rates (ORR) of $16-53 \%$ and a median progressionfree survival (PFS) of 4.5-7.3 months these outcomes are clearly inferior to the efficacy outcomes of selective tyrosine kinase inhibitors (TKI) in other oncogene-addicted NSCLC. Additionally, multi-kinase inhibition in RET-driven NSCLC patients showed concerning rates of high-grade toxicity, mainly induced by anti-VEGFR-kinase activity. Novel selective RET inhibitors like BLU-667, LOXO-292 and RXDX-105 have been recently investigated in early phase clinical trials showing promising efficacy with a manageable toxicity profile.
\end{abstract} Keywords: RET, NSCLC, LOXO-292, BLU-667, RXDX-105, selective RET-inhibition

\section{Introduction}

NSCLC is a heterogeneous disease with the occurrence of a variety of molecular aberrations especially found in cancers with non-squamous histology. At present sensitizing alterations of the epithelial growth factor receptor (EGFR), the anaplastic lymphoma kinase (ALK), the proto-oncogene tyrosine-protein kinase ROS1 (ROS1) and the serine/threonine-protein kinase B-Raf (BRAF) are targetable with approved small molecules resulting in a significant improvement of clinical outcomes. $^{1-5}$ Approximately $1-2 \%$ of unselected patients with NSCLC harbor RET rearrangements. RET rearrangement is more common in patients with adenocarcinoma histology, younger age (<60 years) and in never- or light smokers. ${ }^{6-14}$ The RET receptor tyrosine kinase consists of an extracellular, a transmembrane and an intracellular kinase domain. ${ }^{15,16}$ Signaling is modulated by ligands belonging to the glial-derived neurotrophic factor (GDNF) family, including GDNF, artemin (ARTN), neurturin (NRTN) and persephin (PSPN). ${ }^{17}$ Differing from other receptor tyrosine kinases, ligands bind to one out of four co-receptors of the GDNF family receptor- $\alpha(\mathrm{GFR} \alpha)$ proteins, forming a complex that promotes RET homodimerization, trans-autophosphorylation and the activation of multiple downstream pathways (RAS/MAPK/ERK, PI3K/AKT, JAK/STAT) resulting in enhanced cell survival, proliferation, transformation, migration and angiogenesis. ${ }^{18-26}$ RET oncogenic gene fusion results in the transcription of tumorigenic fusion proteins leading to constitutive kinase activation and ligand-independent pathway triggering. ${ }^{27}$
Correspondence: Raffaele Califano Department of Medical Oncology, The Christie NHS Foundation Trust, Wilmslow Road, Manchester M20 4BX, UK

Tel +44 I6I 4463745

Email raffaele.califano@christie.nhs.uk 
Immunohistochemistry (IHC) has low sensitivity (55$65 \%$ ) in detecting RET-fusion genes and is inadequate and unreliable for diagnostic testing. ${ }^{6,28}$ Break-apart fluorescence in situ hybridization (FISH) represents a highly sensitive diagnostic tool for RET-fusion detection but may not reveal information about the specific gene fusion partner. Reverse transcription polymerase chain reaction (RT-PCR), next-generation sequencing (NGS) and anchored multiplex PCR are complementary tests with the ability to detect specific RET-fusion partners and concurrent genomic alterations. ${ }^{7,28-34}$ The fusion transcript of the kinesin family 5B gene (KIF5B) and RET is the most common RET-fusion partner in NSCLC. ${ }^{7,16,28,30,31,35,36}$ Other frequent fusion partners are protein 6 (CCDC6), nuclear receptor coactivator 4 (NCOA4) and tripartite motif-containing 33 (TRIM33). ${ }^{6,10}$

Multi-target tyrosine kinase inhibition has been the initial treatment strategy for RET-rearranged NSCLC. More recently, early clinical trials investigating novel next-generation selective RET inhibitors (BLU-667, LOXO-292 and RXDX-105) have been reported and showed promising activity.

In this review, we discuss potential treatment approaches for RET-rearranged NSCLC and we summarize the results of trial evaluating multi-kinase inhibitors as well as of novel selective next-generation RET-inhibitors.

\section{Multi-Kinase Inhibitors With Anti-RET Activity Vandetanib}

Vandetanib is an inhibitor of the vascular endothelial growth factor receptor (VEGFR) 2 and 3, epidermal growth factor receptor (EGFR) and RET. RET inhibition occurs through competitive ATP binding in the active conformation of the RET kinase, interrupting downstream signaling. ${ }^{37}$ Subgroup analyses of four randomized Phase III trials have explored the efficacy of vandetanib in pretreated advanced NSCLC in combination with docetaxel $(Z O D I A C)^{38}$ or pemetrexed (ZEAL) $)^{39}$ or monotherapy (ZEPHYR and ZEST). ${ }^{40,41}$ Seven out of 937 patients $(0.7 \%)$ with RET rearrangement were identified. None of the three patients exposed to vandetanib showed an objective response. The Japanese Phase II LURET trial investigated 17 patients with RET-rearranged NSCLC previously exposed to $\geq 1$ line of chemotherapy. ORR was $53 \%$, PFS and $O S$ were 4.7 and 11.1 months, respectively. Patients with a CCDC6-RET fusion had higher ORR (83\% vs
$20 \%$ ) and longer progression-free survival (PFS) (8.3 vs 2.9 months) compared to patients with the KIF5B-RET fusion. $^{42}$ A South Korean Phase II study investigated vandetanib in 18 patients with RET-rearranged NSCLC after failure of at least one line of platinum-based chemotherapy. ORR was $18 \%$, PFS 4.5 months and OS 11.6 months. $^{43}$ In the retrospective Global RET Registry (GLORY) cohort, that was started in 2015 to systematically capture outcomes of RET rearranged NSCLC patients treated with anti-RET therapy outside a clinical trial, 11 patients were treated with vandetanib. ORR, PFS and OS were 18\%, 2.9 months and 10.2 months, respectively. ${ }^{10}$ The most relevant adverse events (AEs) of vandetanib were diarrhea, rash, hypertension and asymptomatic QT prolongation. Dose reduction rate and treatment discontinuation rate were $20 \%$ and $50 \%$, respectively. ${ }^{43}$

\section{Cabozantinib}

Cabozantinib predominantly inhibits VEGFR, C-Met and RET. In a Phase II trial evaluating 26 NSCLC patients with RET rearrangement, 16 (62\%) patients were identified with the KIF5B-RET fusion subtype. ORR was $28 \%$, PFS 5.5 months and OS 9.9 months. ORR in KIF5B-RET patients was $20 \%$ compared to $50 \%$ in tumours with other gene fusion rearrangements. ${ }^{44}$ Twenty-one patients included in the GLORY cohort received Cabozantinib. ORR was $33 \%$, with one patient achieving a complete response. PFS and OS were 3.6 and 4.9 months, respectively. ${ }^{10}$ Most frequently reported grade 3-4 AEs were lipase increase (15\%), liver transaminase increase (8\%) and hypertension (4\%) Dose reduction and discontinuation rate in the Phase II trial were $73 \%$ and $8 \%$, respectively. ${ }^{44}$

\section{Lenvatinib}

Lenvatinib shows anti-TKI activity against VEGFR 1-3, fibroblast growth factor (FGFR) 1-4, platelet-derived growth factor receptor alpha (PDGFR $\alpha$ ), c-KIT and RET. $^{45}$ A combined Japanese and US Phase II trial investigated 25 patients with RET aberrant NSCLC. ${ }^{46}$ Forty percent of patients received one previous line of therapy and $60 \%$ had $\geq 2$ lines of systemic treatment. Of note, 7 (28\%) patients were exposed to a previous anti-RET targeted therapy. ORR was $16 \%$ and PFS 7.3 months. Notably, ORR in patients with previous anti-RET therapy was $14 \%$. Lenvatinib was not well tolerated, with $92 \%$ of patients experiencing grade $\geq 3$ AEs and $3(12 \%)$ fatal AEs of which one was due to pneumonia. Sixty-four percent of 
patients needed a dose reduction and there was a $20 \%$ treatment-related discontinuation rate. The most common reported toxicities (any grade) were hypertension (68\%), nausea $(60 \%)$, anorexia $(52 \%)$, diarrhoea $(52 \%)$, proteinuria $(48 \%)$ and vomiting $(44 \%){ }^{46}$

\section{Alectinib}

Alectinib is an inhibitor of ALK, RET, receptor-type tyrosine-protein kinase FLT3 (FLT3), kinase 2 and leukocyte receptor tyrosine kinase. Notably, Alectinib does not inhibit VEGF-R, which might be an advantage over other antiRET TKIs with antiangiogenic side effects. Pre-clinically, alectinib strongly inhibited RET kinase activity and suppressed growth of RET-fusion-positive cells in cell lines and xenograft models expressing KIF5B-RET and CCDC6-RET. Alectinib also showed promising in vitro activity against common RET gatekeeper mutations (RET V804L and V804M). ${ }^{47}$ Retrospective observations report two out of six (33\%) patients with a partial response treated with alectinib. ${ }^{10,48}$

Several early phase clinical trials investigating alectinib in RET rearranged NSCLC patients are ongoing. The Phase I/II study NCT03131206 includes a cohort of RET-rearranged NSCLC patients and is expected to complete enrolment in 2020. The Phase II study ALERT-lung (NCT03445000) will enrol 44 patients treated with at least one line of platinumbased therapy and the expected completion date is June 2022. The DARWIN II study (NCT02314481), an exploratory Phase II study, will include patients with ALK/RET gene rearrangement who will be treated with alectinib. Estimated completion date is January 2023.

\section{Sunitinib}

Sunitinib inhibits c-KIT, VEGFR1-3, platelet-derived growth factor receptor beta (PDGFRB), FLT3 and RET. In the GLORY cohort, nine patients received sunitinib. The reported ORR was $22 \%$ with two patients experiencing a partial response. ${ }^{10}$

\section{Ponatinib}

Ponatinib inhibits a broad spectrum of kinases with profound activity against BCR-ABL, VEGFR, FLT3, FGFR, c-KIT ant RET. It showed profound anti-RET activity in preclinical xenograft models harbouring KIF5B-RET and CCDC6-RET. The half-maximum inhibitory concentration of ponatinib was remarkably lower compared to other TKIs like cabozantinib, vandetanib or lenvatinib. ${ }^{49}$ Two patients treated with ponatinib in the GLORY cohort experienced disease stabilization as the best response. ${ }^{10}$ A Phase II study (NCT01813734) investigating ponatinib in RET rearranged advanced NSCLC patients has closed recruitment after enrolling 9 patients and results are awaited.

\section{Sorafenib}

Sorafenib is a multi-target TKI with inhibiting activity against CRAF, BRAF, KIT, FLT3, VEGFR and RET. In a preclinical analysis activity against KIF5B-RET fusions has been observed. ${ }^{28}$ In a Phase II trial, 3 patients with RET-rearrangement NSCLC were treated with sorafenib and no responses were observed. ${ }^{50}$

\section{Vandetanib Plus Everolimus}

Clinical and pre-clinical (cell-lines) activity of vandetanib plus everolimus has been assessed in a Phase I trial. Thirteen patients were RET rearranged by NGS or FISH. Although ORR was 54\%, median PFS was only 4.4 months. Grade 3 and 4 toxicities were diarrhoea (21\%), thrombocytopenia (16\%), QTc prolongation $(5 \%)$ and $\operatorname{rash}(5 \%){ }^{51}$

\section{Novel New Generation Selective RET Inhibitors LOXO-292}

LOXO-292 is a highly selective oral TKI particularly developed with profound anti-kinase activity against RET rearranged tumors. The Phase I/II LIBRETTO-001 basket trial (NCT03157128) is investigating the safety, tolerability, pharmacokinetics and preliminary antitumor activity of LOXO-292 in patients with RET rearranged solid tumors. First results of RET-driven NSCLC patients have been recently reported at the American Society of Clinical Oncology Annual (ASCO) 2018 annual meeting and updated at the 19th IASLC World Conference of Lung Cancer (WCLC). So far, 38 patients with RET-rearranged NSCLC have been evaluated. Patients were heavily pretreated with a median of three lines of previous therapy including multi-kinase inhibition (55\%), platinum-based chemotherapy and anti-PD-(L)1 therapy. The most common RET fusion partner was KIF5B $(n=16)$, followed by CCDC6 $(\mathrm{n}=11)$. Objective response rate was $68 \%$, with 26 patients showing a partial response. Six additional patients showed tumour shrinkage between $-3 \%$ and $-29 \%$. All patients with target lesions in the brain $(n=4)$ showed intracranial response with one complete response 
and three partial responses. Antitumor activity was observed regardless of previous treatment, central nervous system (CNS) metastases or RET fusion partner. After a median follow-up of 8.5 months, 25 of 26 (96\%) responding patients remained on treatment. The longest duration of response was $>14$ months.

Most common treatment-related side effects were grade $1-2$ : diarrhea $(23 \%)$, fatigue $(22 \%)$, dry mouth (21\%). Only 4 out of $82(4.8 \%)$ patients included in the safety analysis showed treatment-related grade 3 adverse events. These included tumour lysis syndrome, increased ALT/AST, diarrhoea and thrombocytopenia. All of them were reversible after dose interruption. ${ }^{52,53}$

\section{BLU-667}

BLU-667 is another oral drug engineered to specifically inhibit RET. Preclinical investigations showed that the selectivity of BLU-667 for RET is more than 100 times higher compared to other tested multi-kinase inhibitors. ${ }^{54}$ BLU-667 has been investigated in the Phase I ARROW basket study (NCT03037385) to define safety, tolerability and preliminary antitumor activity. Preliminary findings of the ARROW study were presented at the American Association of Cancer Research (AACR) Annual Meeting in 2018. More than half of the included patients were exposed to previous anti-RET multi-kinase inhibitors. Nineteen patients with RET-rearranged NSCLC received BLU-667 and achieved a ORR of $50 \%$. Responses were seen regardless of fusion partner or type and number of prior treatments. At data cut-off, PFS and OS data were not mature. BLU-667 was very well tolerated; the incidence of grade 3 toxicity was $6.9 \%$ and included ALT increase, tumor lysis and hypertension. No grade 4-5 adverse events have been reported. ${ }^{55}$

\section{RXDX- 105}

RXDX-105 is a VEGFR-sparing selective RET inhibitor with activity across a variety of RET-rearranged solid tumors. ${ }^{56,57}$ Safety outcomes and preliminary antitumor activity results of RXDX-105 were evaluated in a Phase $\mathrm{I} / \mathrm{Ib}$ study that has just recently been published. ${ }^{58}$ Forty patients with RET rearranged NSCLC were included of which nine $(22.5 \%)$ patients had received previous multikinase inhibitory anti-RET therapy. Overall ORR was 19\% and no responses were observed in patients with KIF5BRET fusions, while patients with non-KIF5B RET partners achieved an ORR of $67 \%$. The median duration of response was not reached and ranged from 5 to $18+$ months. The most common treatment-related AEs were fatigue $(25 \%)$, diarrhea (24\%), hypophosphatemia (18\%), maculopapular rash (18\%) and non-maculopapular rash $(17 \%)$. No grade $\geq 4$ toxicity was observed. ${ }^{58}$

\section{Immunotherapy (IO) with checkpoint inhibitors (CPI) in RET- rearranged NSCLC}

While in recent times IO with CPI has been a milestone in lung cancer care, there is only limited data on CPI activity in patients with oncogenic drivers and the efficacy of IO in RET-rearranged lung cancer has not been well characterized yet. In patients with EGFR-mutant tumors, current data suggest only very limited activity of single agent CPI, even in the presence of a high PD-L1 expression. ${ }^{59,60} \mathrm{~A}$ recently presented analysis investigating the responsiveness of RET-activated solid tumors to CPI within the Phase I clinical trial program at the MD Anderson Cancer Center $(n=72, N S C L C=29)$ showed a shorter time to progression (TTP) in patients treated with a CPI compared to patients treated with a non-CPI containing treatment. ${ }^{61}$ Another retrospective analysis investigated the efficacy of CPI in NSCLC with different activating molecular aberrations. Patients under single agent CPI therapy with an EGFR-, ALK- or RET-aberration had the worst outcome with a PFS of approximately two months, while patients with a HER2-, MET- or BRAF-aberration had a slightly better but still very poor outcome (PFS 3.23-5 months). ${ }^{62}$ Drilon and colleagues retrospectively assessed 74 RET rearranged lung cancer patients treated with CPI at the Memorial Sloan Kettering Cancer Center. The study showed that the immunophenotype of RETaberrant tumours was characterized by low levels of PDL1 expression ( $81 \%$ with no $(0 \%)$ or low levels $(1-49 \%)$ of PD-L1 expression) and low Tumour-Mutational-Burden (TMB). The median line of therapy at which immunotherapy was administered was 2 (range, 1 to 7). No responses were observed in 13 patients suitable for radiological assessment. Median PFS in all patients was 3.4 months and even in the highest levels of PD-L1 expression $(\geq 50 \%$ and $\geq 30 \%$ ) PFS was short (1.3 months and 2.5 months, respectively). There was no difference in OS in patients treated with or without CPI (HR, 1.4 (95\% CI, 0.7-2.9, $\mathrm{P}=0.35){ }^{63}$ According to current knowledge, no recommendation regarding the use of CPI in RET-rearranged NSCLC can be made. 


\section{Discussion}

Cabozantinib, vandetanib and lenvatinib have been extensively investigated in several early phase trials evaluating RET-altered NSCLC patients. The clinical activity of these agents appeared to be modest with ORR ranging between $16 \%$ and $53 \%$ depending on the RET-fusion partner and a PFS of 2.9-7.3 months. Furthermore, multi-kinase RET TKIs are often associated with high rates of toxicity due to off-target kinase inhibition mainly caused by the activity against VEGFR (hypertension, proteinuria, palmoplantar erythrodysesthesia) and EFGR (diarrhea, skin rashes). Lenvatinib, in particular, showed poor tolerability due to high rate of severe treatmentrelated AEs. Dose reductions and treatment discontinuations were frequent (up to $70 \%$ ) in patients treated with multi-kinase RET inhibitors.

The early phase clinical outcomes of the novel selective and more potent RET inhibitors LOXO-929, BLU-667 and RXDX-105 showed promise to overcome the limitations of multi-kinase RET inhibitors with enhanced activity and manageable toxicity. LOXO-292 showed an ORR of $68 \%$ in heavily pretreated patients, irrespective of the RET-fusion partner and substantial intracranial activity with no safety concerns. ${ }^{55}$ RXDX-105 as well showed good tolerability but ORR was considerably higher (67\%) in patients with non-KIF5B-RET fusions, while none of the patient with a KIF5B-RET fusion showed a response. $^{58}$ BLU-667 was well tolerated and induced responses in $50 \%$ of patients regardless of the RET-fusion partner or previous therapy lines. ${ }^{55}$

Table 1 summarizes the clinical data of the multi-kinas RET-inhibitors cabozantinib, vandetanib, vandetanib plus everolimus and lenvatininb as well as of the novel RETspecific inhibitors. Figure 1 illustrates the corresponding ORRs. A recently presented US American study group presented the first example of clinical response to combined EGFR plus RET inhibition with BLU-667 plus osimertinib in a patient with acquired RET-fusion resistance on osimertinib. Acquired RET-fusion resistance after osimertinib in EGFR-mutant NSCLC patients occurs in about $4 \%$ of patients. ${ }^{64}$ The anti-RET/anti-EGFR therapy was well tolerated and induced significant clinical benefit within a few days and deep response $(-78 \%$ tumour shrinkage) after 8 weeks of treatment. ${ }^{65}$ The combination of osimertinib plus BLU-667 might be a tolerable and effective regimen to overcome TKI resistance in patients with EGFR mutant and possibly also in other TKI targetable driver mutations with acquired RET rearrangement.

These early trial preliminary efficacy results provide proof of concept and encouraging evidence that RET rearranged NSCLC are potentially treatable with specific RET inhibitors. Further investigations of selective RET

Table I Summary Of Clinical Data Of RET-Inhibitors

\begin{tabular}{|c|c|c|c|c|c|c|c|c|c|}
\hline Trial & $\begin{array}{l}\text { Study } \\
\text { phase }\end{array}$ & $\begin{array}{l}\text { RET } \\
\text { Inhibitor }\end{array}$ & Pharmacodynamic & No & $\begin{array}{l}\text { ORR } \\
\text { (\%) }\end{array}$ & $\begin{array}{l}\text { PFS } \\
\text { (Months) }\end{array}$ & $\begin{array}{l}\text { OS } \\
\text { (Months) }\end{array}$ & $\begin{array}{l}\text { Grade } \\
\geq 3 \text { AEs } \\
(\%)\end{array}$ & $\begin{array}{l}\text { Discontinuation } \\
\text { Rate (\%) }\end{array}$ \\
\hline $\begin{array}{l}\text { Drilon et al } \\
2016^{44}\end{array}$ & II & Cabozantinib & Multi-kinase inhibitor & 26 & 28 & 5.5 & 9.9 & 69 & 8 \\
\hline $\begin{array}{l}\text { Yoh et al } 2017 \\
\text { (LURET) }\end{array}$ & II & Vandetanib & Multi-kinase inhibitor & 19 & 53 & 4.7 & $N / R$ & $N / R$ & II.I \\
\hline Lee et al, $2017^{43}$ & II & Vandetanib & Multi-kinase inhibitor & 18 & 18 & 4.5 & 11.6 & 27 & $N / R$ \\
\hline $\begin{array}{l}\text { Velcheti et al, } \\
2017^{46}\end{array}$ & II & Lenvatinib & Multi-kinase inhibitor & 25 & 16 & 7.3 & $N / R$ & 92 & 20 \\
\hline Subbiah et al. ${ }^{51}$ & & $\begin{array}{l}\text { Vandetanib } \\
\text { +Everolimus }\end{array}$ & $\begin{array}{l}\text { Multi-kinase inhibitor } \\
+ \text { mTOR inhibitor }\end{array}$ & 13 & 54 & 4.4 & $N / R$ & $N / R$ & $N / R$ \\
\hline $\begin{array}{l}\text { Oxnard et al, } \\
2018^{53} \\
\text { (LIBRETTO-00I) }\end{array}$ & $1 / I I$ & LOXO-292 & $\begin{array}{l}\text { Selective RET } \\
\text { inhibitor }\end{array}$ & 38 & 68 & $N / R$ & $N / R$ & 4.8 & 0 \\
\hline $\begin{array}{l}\text { Subbiah et al, } \\
2018^{54,55} \\
\text { (ARROW) }\end{array}$ & 1 & BLU-667 & $\begin{array}{l}\text { Selective RET } \\
\text { inhibitor }\end{array}$ & 19 & 50 & $N / R$ & $N / R$ & 6.9 & $N / R$ \\
\hline $\begin{array}{l}\text { Drilon et al, } \\
2018^{58}\end{array}$ & $\mathrm{l} / \mathrm{lb}$ & $R \times D X-105$ & $\begin{array}{l}\text { Selective RET } \\
\text { inhibitor }\end{array}$ & 40 & 19 & $N / R$ & $N / R$ & 35 & 16 \\
\hline
\end{tabular}

Abbreviation: $N / R$, not reported. 


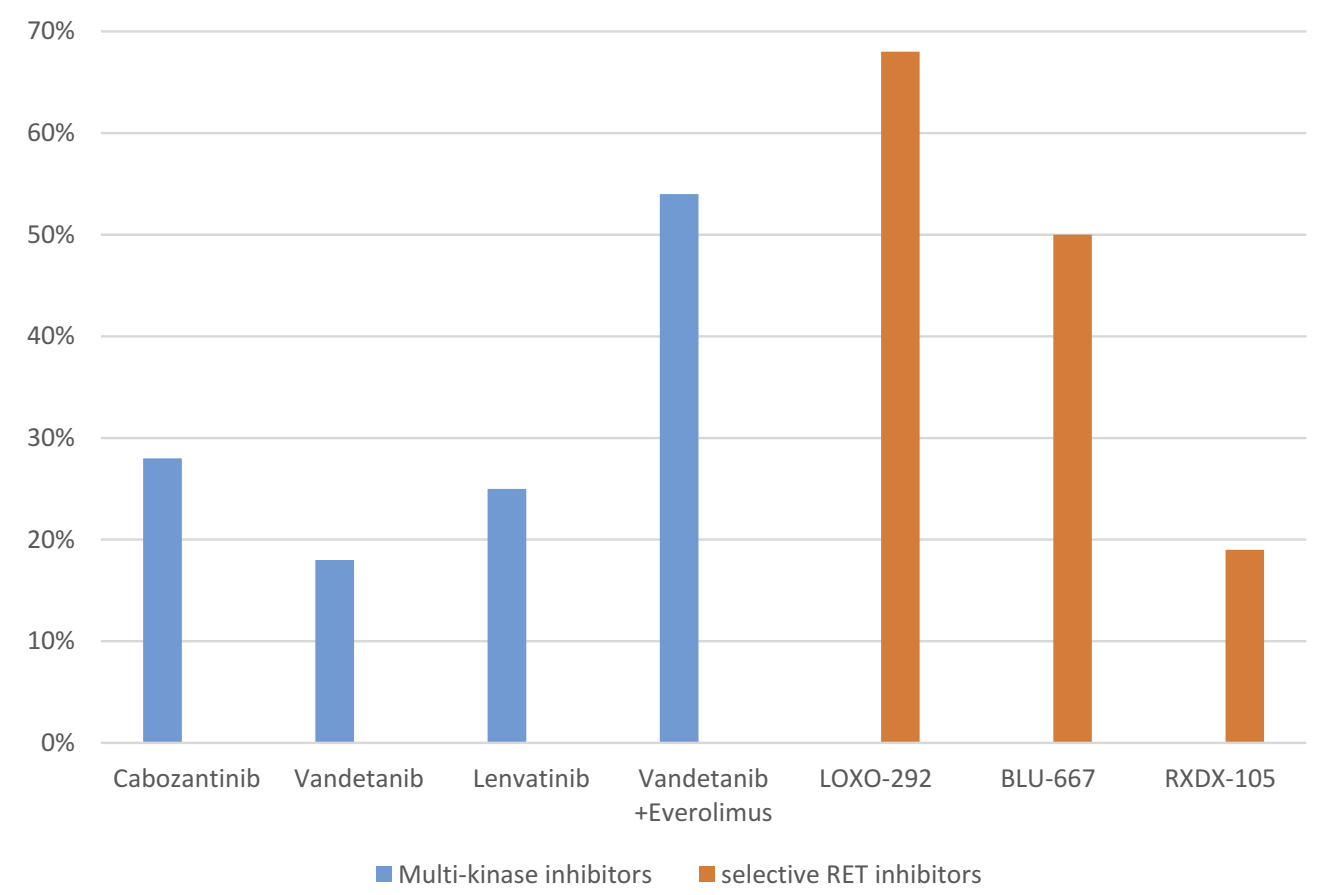

Figure I Reported objective response rates of multi-kinase inhibitors and selective RET-inhibitors. Cabozantinib, ${ }^{44}$ Vandetanib, ${ }^{43}$ Lenvatinib, ${ }^{46}$ LOXO-292, ${ }^{53}$ BLU-667, ${ }^{54,55}$ RXDX-105..$^{58}$

inhibitors in larger patient cohorts are now needed to assess CNS activity, explore and identify potential mechanisms of acquired resistance to multi-kinase and selective RET inhibition, assess the impact of different RET-fusion variants and also identify optimal treatment sequences of RET targeted therapy options.

\section{Conclusion}

Genomic profiling has revolutionized treatment options for patients with EGFR-, ALK-, ROS1- and BRAF-driven NSCLC. Promising results of recent early phase clinical trials show that for RET-driven lung tumours, selective RET inhibitors like LOXO-292, BLU-667 and RXDX-105 represent better therapeutic options than multi-target TKIs due to enhanced clinical activity and better tolerability. Results of later phase studies are eagerly awaited to fully evaluate the potential of these drugs and proved have further insight into the toxicity profile.

\section{Disclosure}

Dr. Raffaele Califano reports personal fees and non-financial support from AstraZeneca, MSD, BMS, Roche, Takeda, Pfizer, and Novartis outside the submitted work. The authors report no other conflicts of interest in this work.

\section{References}

1. Kohno T, Nakaoku T, Tsuta K, et al. Beyond ALK-RET, ROS1 and other oncogene fusions in lung cancer. Transl Lung Cancer Res. 2015;4:156-164. doi:10.3978/j.issn.2218-6751.2014.11.11

2. Bergethon K, Shaw AT, Ou SH, et al. ROS1 rearrangements define a unique molecular class of lung cancers. J Clin Oncol. 2012;30:863870. doi:10.1200/JCO.2011.35.6345

3. Shaw AT, Kim DW, Nakagawa K, et al. Crizotinib versus chemotherapy in advanced ALK-positive lung cancer. $N$ Engl $J$ Med. 2013;368:2385-2394. doi:10.1056/NEJMoa1214886

4. Paz-Ares L, Tan EH, O'Byrne K, et al. Afatinib versus gefitinib in patients with EGFR mutation-positive advanced non-small-cell lung cancer: overall survival data from the phase IIb LUX-lung 7 trial. Ann Oncol. 2017;28:270-277. doi:10.1093/annonc/mdw611

5. Planchard D, Besse B, Groen HJM, et al. Dabrafenib plus trametinib in patients with previously treated $\mathrm{BRAF}(\mathrm{V} 600 \mathrm{E})$-mutant metastatic non-small cell lung cancer: an open-label, multicentre phase 2 trial. Lancet Oncol. 2016;17:984-993. doi:10.1016/S1470-2045(16) 30146-2

6. Wang R, Hu H, Pan Y, et al. RET fusions define a unique molecular and clinicopathologic subtype of non-small-cell lung cancer. J Clin Oncol. 2012;30:4352-4359. doi:10.1200/JCO.2012.44.1477

7. Tsuta K, Kohno T, Yoshida A, et al. RET-rearranged non-small-cell lung carcinoma: a clinicopathological and molecular analysis. $\mathrm{Br} J$ Cancer. 2014;110:1571-1578. doi:10.1038/bjc.2014.36

8. Pan Y, Zhang Y, Li Y, et al. ALK, ROS1 and RET fusions in 1139 lung adenocarcinomas: a comprehensive study of common and fusion pattern-specific clinicopathologic, histologic and cytologic features. Lung Cancer. 2014;84:121-126. doi:10.1016/j.lungcan.2014. 02.007

9. Lin C, Wang S, Xie W, Chang J, Gan Y. The RET fusion gene and its correlation with demographic and clinicopathological features of nonsmall cell lung cancer: a meta-analysis. Cancer Biol Ther. 2015;16:1019-1028. doi:10.1080/15384047.2015.1046649 
10. Gautschi O, Milia J, Filleron T, et al. Targeting RET in patients with RET-rearranged lung cancers: results from the global, multicenter RET registry. J Clin Oncol. 2017;35:1403-1410. doi:10.1200/ JCO.2016.70.9352

11. Chao BH, Briesewitz R, Villalona-Calero MA. RET fusion genes in non-small-cell lung cancer. J Clin Oncol. 2012;30:4439-4441. doi:10.1200/JCO.2012.45.8240

12. Klempner SJ, Bazhenova LA, Braiteh FS, et al. Emergence of RET rearrangement co-existing with activated EGFR mutation in EGFRmutated NSCLC patients who had progressed on first- or secondgeneration EGFR TKI. Lung Cancer. 2015;89:357-359. doi:10.1016/ j.lungcan.2015.06.021

13. Kim JO, Lee J, Shin JY, et al. KIF5B-RET fusion gene may coincide oncogenic mutations of EGFR or KRAS gene in lung adenocarcinomas. Diagn Pathol. 2015;10:143. doi:10.1186/s13000-0150368-z

14. Drilon A, Bergagnini I, Delasos L, et al. Clinical outcomes with pemetrexed-based systemic therapies in RET-rearranged lung cancers. Ann Oncol. 2016;27:1286-1291. doi:10.1093/annonc/mdw163

15. Takahashi M, Buma $Y$, Iwamoto $T$, Inaguma $Y$, Ikeda $H$, Hiai $H$. Cloning and expression of the ret proto-oncogene encoding a tyrosine kinase with two potential transmembrane domains. Oncogene. 1988;3:571-578

16. Eng C. RET proto-oncogene in the development of human cancer. $J$ Clin Oncol. 1999;17:380-393. doi:10.1200/JCO.1999.17.1.380

17. Airaksinen MS, Saarma M. The GDNF family: signalling, biological functions and therapeutic value. Nat Rev Neurosci. 2002;3:383-394. doi:10.1038/nrn812

18. Worby CA, Vega QC, Zhao Y, Chao HH, Seasholtz AF, Dixon JE. Glial cell line-derived neurotrophic factor signals through the RET receptor and activates mitogen-activated protein kinase. J Biol Chem. 1996;271:23619-23622. doi:10.1074/jbc.271.39.23619

19. Takahashi M. The GDNF/RET signaling pathway and human diseases. Cytokine Growth Factor Rev. 2001;12:361-373.

20. Schuringa JJ, Wojtachnio K, Hagens W, et al. MEN2A-RET-induced cellular transformation by activation of STAT3. Oncogene. 2001;20:5350-5358. doi:10.1038/sj.onc.1204715

21. Plaza-Menacho I, Burzynski GM, de Groot JW, Eggen BJ, Hofstra RM. Current concepts in RET-related genetics, signaling and therapeutics. Trends Genet. 2006;22:627-636. doi:10.1016/j.tig.2006.09. 005

22. Phay JE, Shah MH. Targeting RET receptor tyrosine kinase activation in cancer. Clin Cancer Res. 2010;16:5936-5941. doi:10.1158/ 1078-0432.CCR-09-0786

23. Mulligan LM. RET revisited: expanding the oncogenic portfolio. Nat Rev Cancer. 2014;14:173-186. doi:10.1038/nrc3680

24. Maeda K, Murakami H, Yoshida R, et al. Biochemical and biological responses induced by coupling of Gab1 to phosphatidylinositol 3kinase in RET-expressing cells. Biochem Biophys Res Commun 2004;323:345-354. doi:10.1016/j.bbrc.2004.08.095

25. Arighi E, Borrello MG, Sariola H. RET tyrosine kinase signaling in development and cancer. Cytokine Growth Factor Rev. 2005;16:441467. doi:10.1016/j.cytogfr.2005.05.010

26. Andreozzi F, Melillo RM, Carlomagno F, et al. Protein kinase Calpha activation by RET: evidence for a negative feedback mechanism controlling RET tyrosine kinase. Oncogene. 2003;22:2942-2949. doi:10.1038/sj.onc. 1206475

27. Qian Y, Chai S, Liang Z, et al. KIF5B-RET fusion kinase promotes cell growth by multilevel activation of STAT3 in lung cancer. Mol Cancer. 2014;13:176. doi:10.1186/1476-4598-13-176

28. Lipson D, Capelletti M, Yelensky R, et al. Identification of new ALK and RET gene fusions from colorectal and lung cancer biopsies. Nat Med. 2012;18:382-384. doi:10.1038/nm.2673

29. Mellert H. Early feasibility and development of multiplexed, singlereaction assays for ALK, ROS1 and RET novel ddPCR RNA fusions. Abstract 1774. Cancer Res. 2017;77(13Supplement):1784.
30. Kohno T, Ichikawa H, Totoki Y, et al. KIF5B-RET fusions in lung adenocarcinoma. Nat Med. 2012;18:375-377. doi:10.1038/ nm. 2644

31. Ju YS, Lee WC, Shin JY, et al. A transforming KIF5B and RET gene fusion in lung adenocarcinoma revealed from whole-genome and transcriptome sequencing. Genome Res. 2012;22:436-445. doi:10. 1101/gr.133645.111

32. Cai W, Su C, Li X, et al. KIF5B-RET fusions in Chinese patients with non-small cell lung cancer. Cancer. 2013;119:1486-1494. doi: $10.1002 /$ cncr. 27940

33. Go H, Jung YJ, Kang HW, et al. Diagnostic method for the detection of KIF5B-RET transformation in lung adenocarcinoma. Lung Cancer. 2013;82:44-50. doi:10.1016/j.lungcan.2013.07.009

34. Drilon A, Wang L, Arcila ME, et al. Broad, hybrid capture-based next-generation sequencing identifies actionable genomic alterations in lung adenocarcinomas otherwise negative for such alterations by other genomic testing approaches. Clin Cancer Res. 2015;21:36313639. doi:10.1158/1078-0432.CCR-14-2683

35. Grieco M, Santoro M, Berlingieri MT, et al. PTC is a novel rearranged form of the ret proto-oncogene and is frequently detected in vivo in human thyroid papillary carcinomas. Cell. 1990;60:557-563. doi:10.1016/0092-8674(90)90659-3

36. Li F, Feng Y, Fang R, et al. Identification of RET gene fusion by exon array analyses in "pan-negative" lung cancer from never smokers. Cell Res. 2012;22:928-931. doi:10.1038/cr.2012.27

37. Plaza-Menacho I, Mologni L, McDonald NQ. Mechanisms of RET signaling in cancer: current and future implications for targeted therapy. Cell Signal. 2014;26:1743-1752. doi:10.1016/j.cellsig.20 14.03 .032

38. Herbst RS, Sun Y, Eberhardt WE, et al. Vandetanib plus docetaxel versus docetaxel as second-line treatment for patients with advanced non-small-cell lung cancer (ZODIAC): a double-blind, randomised, phase 3 trial. Lancet Oncol. 2010;11:619-626. doi:10.1016/S14702045(10)70132-7

39. de Boer RH, Arrieta O, Yang $\mathrm{CH}$, et al. Vandetanib plus pemetrexed for the second-line treatment of advanced non-small-cell lung cancer: a randomized, double-blind phase III trial. $J$ Clin Oncol. 2011;29:1067-1074. doi:10.1200/JCO.2010.29.5717

40. Natale RB, Thongprasert S, Greco FA, et al. Phase III trial of vandetanib compared with erlotinib in patients with previously treated advanced non-small-cell lung cancer. $J$ Clin Oncol. 2011;29:1059-1066. doi:10.1200/JCO.2010.28.5981

41. Lee JS, Hirsh V, Park K, et al. Vandetanib Versus placebo in patients with advanced non-small-cell lung cancer after prior therapy with an epidermal growth factor receptor tyrosine kinase inhibitor: a randomized, double-blind phase III trial (ZEPHYR). J Clin Oncol. 2012;30:1114-1121. doi:10.1200/JCO.2011.36.1709

42. Yoh K, Seto T, Satouchi M, et al. Vandetanib in patients with previously treated RET-rearranged advanced non-small-cell lung cancer (LURET): an open-label, multicentre phase 2 trial. Lancet Respir Med. 2017;5:42-50. doi:10.1016/S2213-2600(16)30322-8

43. Lee SH, Lee JK, Ahn MJ, et al. Vandetanib in pretreated patients with advanced non-small cell lung cancer-harboring RET rearrangement: a phase II clinical trial. Ann Oncol. 2017;28:292-297. doi:10.1093/ annonc/mdw559

44. Drilon A, Rekhtman N, Arcila M, et al. Cabozantinib in patients with advanced RET-rearranged non-small-cell lung cancer: an open-label, single-centre, phase 2, single-arm trial. Lancet Oncol. 2016;17:16531660. doi:10.1016/S1470-2045(16)30562-9

45. Suyama K, Iwase H. Lenvatinib: a promising molecular targeted agent for multiple cancers. Cancer Control. 2018;25:107327 4818789361. doi:10.1177/1073274818789361

46. Velcheti V, Hida T, Reckamp KL. Phase 2 study of lenvatinib (LN) in patients (Pts) with RET fusion-positive adenocarcinoma of the lung. Ann Oncol. 2016;27(suppl_6):1204PD-1204PD. doi:10.1093/annonc/ mdw383.05 
47. Kodama T, Tsukaguchi T, Satoh Y, et al. Alectinib shows potent antitumor activity against RET-rearranged non-small cell lung cancer. Mol Cancer Ther. 2014;13:2910-2918. doi:10.1158/1535-7163.MCT14-0274

48. Lin JJ, Kennedy E, Sequist LV, et al. Clinical activity of alectinib in advanced RET-rearranged non-small cell lung cancer. $J$ Thorac Oncol. 2016;11:2027-2032. doi:10.1016/j.jtho.2016.08.126

49. Gozgit JM, Chen TH, Song Y, et al. RET fusions observed in lung and colorectal cancers are sensitive to ponatinib. Oncotarget. 2018;9:29654-29664. doi:10.18632/oncotarget.25664

50. Horiike A, Takeuchi K, Uenami T, et al. Sorafenib treatment for patients with RET fusion-positive non-small cell lung cancer. Lung Cancer. 2016;93:43-46. doi:10.1016/j.lungcan.2015.12.011

51. Subbiah V, Cascone T, Hess KR, et al. Multi-kinase RET inhibitor vandetanib combined with mTOR inhibitor everolimus in patients with RET rearranged non-small cell lung cancer. JCO. 2018;36:9035. doi:10.1200/JCO.2018.36.15_suppl.9035

52. Drilon A, Subbiah V, Oxnard GR, et al. A phase 1 study of LOXO292, a potent and highly selective RET inhibitor, in patients with RET-altered cancers. J Clin Oncol. 2018;36(15_suppl):102. Abstract 102 presented at ASCO 2018 2018. doi:10.1200/JCO.2018.36. 15_suppl.102

53. Oxnard G, Subbiah V, Park K, et al. Clinical activity of LOXO-292, a highly selective RET inhibitor in patients wit RET fusion positive NSCLC. Abstract 1207 presented at the 19th IASLC World Lung Conference, September 23-26, 2018; Toronto, Canada.

54. Subbiah V, Gainor JF, Rahal R, et al. Precision targeted therapy with BLU-667 for RET-driven cancers. Cancer Discov. 2018;8:836-849. doi:10.1158/2159-8290.CD-18-0338

55. Subbiah V, Taylor M, Lin J. Highly potent and selective RET inhibitor, BLU-667, achieves proof of concept in a phase I study of advanced, RET-altered solid tumors. Cancer Research. Cancer Research 2018;78(13Supplement): CT043-CT043, presented at AACR Annual Meeting 2018, April 14-18, 2018; Chicago, IL.

56. Li GG, Somwar R, Joseph J, et al. Antitumor activity of RXDX-105 in multiple cancer types with RET rearrangements or mutations. Clin Cancer Res. 2017;23:2981-2990. doi:10.1158/1078-0432.CCR-161887
57. Patel MR, Fakih M, Olszanski AJ, et al. A phase 1 dose escalation study of RXDX-105, an oral RET and BRAF inhibitor, in patients with advanced solid tumors. J Clin Oncol. 2016;34(15_suppl):2574. Abstract presented at ASCO 2016 2016. doi:10.1200/JCO.2016. 34.15_suppl.2574

58. Drilon A, Fu S, Patel MR, et al. A phase I/Ib Trial of the VEGFRsparing multikinase RET inhibitor RXDX-105. Cancer Discov. 2019;9:384-395.

59. Lisberg A, Cummings A, Goldman JW, et al. A Phase II study of pembrolizumab in EGFR-mutant, PD-L1+, tyrosine kinase inhibitor naive patients with advanced NSCLC. $J$ Thorac Oncol. 2018;13:1138-1145. doi:10.1016/j.jtho.2018.03.035

60. Lee CK, Man J, Lord S, et al. Checkpoint inhibitors in metastatic EGFR-mutated non-small cell lung cancer-A meta-analysis. J Thorac Oncol. 2017;12:403-407. doi:10.1016/j.jtho.2016.10.007

61. Hegde A, Huang L, Liu S, et al. Responsiveness to immune checkpoint inhibitors in RET dependent cancers. Abstract \#4497 presentet at the Annual American Association for Cancer Research (AACR) meeting, April 30, 2019; Atlanta, USA.

62. Mazieres J, Drilon AE, Mhanna L, et al. Efficacy of immune-checkpoint inhibitors (ICI) in non-small cell lung cancer (NSCLC) patients harboring activating molecular alterations (ImmunoTarget). JCO. 2018;36:9010. doi:10.1200/JCO.2018.36.15_suppl.9010

63. Offin M, Guo R, Wu SL, et al. Immunophenotype and response to immunotherapy of RET-rearranged lung cancers. JCO Precis Oncol. 2019;3.

64. Papadimitrakopoulou VA, Wu Y, Han J, et al. Analysis of resistance mechanisms to osimertinib in patients with EGFR T790M advanced NSCLC from the AURA3 study. Abstract LBA51 presented at the ESMO 2018 Congress; October 19-23, 2018; Munich, Germany.

65. Piotrowska Z, Isozaki H, Lennerz JK, et al. Activity of osimertinib and the selective RET inhibitor BLU-667 in an EGFR-mutant patient with acquired RET rearrangement. Abstract 2603 presented at the 19th IASLC World Lung Conference, September 23-26, 2018; Toronto, Canada

\section{Publish your work in this journal}

OncoTargets and Therapy is an international, peer-reviewed, open access journal focusing on the pathological basis of all cancers, potential targets for therapy and treatment protocols employed to improve the management of cancer patients. The journal also focuses on the impact of management programs and new therapeutic agents and protocols on patient perspectives such as quality of life, adherence and satisfaction. The manuscript management system is completely online and includes a very quick and fair peer-review system, which is all easy to use. Visit http://www.dovepress.com/ testimonials.php to read real quotes from published authors. 